\title{
Probiotic lactic acid bacteria and their potential in the prevention and treatment of allergic diseases
}

\author{
WIOLETTA ŻUKIEWICZ-SOBCZAK ${ }^{1}$, PAULA WRÓBLEWSKA ${ }^{1}$, PIOTR ADAMCZUK', \\ WOJCIECH SILNY²
}

${ }^{1}$ Department of Alergology and Environmental Hazards, Institute of Rural Health, Lublin, Poland

${ }^{2}$ Allergy and Dermatology Center "Art Clinic", Poznan, Poland

\begin{abstract}
Allergy is one of the most important and very common health problems worldwide. To reduce the proportion of people suffering from allergy, alternative methods of prevention and treatment are sought. The aim of this paper is to present the possibilities of probiotics in the prevention and treatment of allergic diseases.

Probiotics are live microorganisms belonging mainly to the lactic acid bacteria. They modify the microflora of the human digestive system, especially the intestinal microflora. Prophylactic administration of probiotics in the early stages of life (naturally in breast milk or milk substitute synthetic compounds) is very important because intestinal microflora plays a huge role in the development of the immune system. Prevention of allergies as early as in the prenatal and postnatal periods provides huge opportunities for inhibiting the growing problem of allergy in emerging and highly developed societies. Effects of probiotic therapy depend on many factors such as the species of the microorganism used, the dose size and characteristics of the bacteria such as viability and capacity of adhesion to the intestinal walls. Authors of several studies showed beneficial effects of probiotics in the perinatal period, infancy, and also in adults in the prevention of atopic dermatitis or allergic rhinitis.

Probiotics, due to their immunomodulatory properties and safety of use are a good, natural alternative for the prevention and treatment of many diseases including allergies. It is therefore important to explore the knowledge about their use and to carry out further clinical trials.
\end{abstract}

Key words: allergy, lactic acid bacteria, probiotics.

(Centr Eur J Immunol 2014; 39 (1): 104-108)

\section{Introduction}

Allergies today are one of common problems of public health. It is estimated that as much as $30-40 \%$ of the world population suffer from allergies. According to current forecasts, the incidence of allergic diseases will continue to grow. Poland is among countries with a high proportion of patients with allergies, and it is estimated that about $40 \%$ of Poles are suffering from allergies [1-5].

For several years now research of probiotic activity on the cellular level, and the impact on the immune system and cells has been carried on. Also many clinical trials on the effect of probiotics on health and functioning of the human body have been conducted. The use of probiotics continues to expand. Currently, it includes the treatment and prevention of many types of diarrhea, including post-antibiotic and infectious diarrhea, irritable bowel syndrome, lactose intolerance treatment, prevention and treatment of allergies and even cancer prevention [6].

\section{Abbreviated description of the state of knowledge}

The word probiotic derives from the Greek "pro bios" for life. Belief in the beneficial properties of fermented milk beverages dates back to biblical times. It is known that in the first century AD, Pliny the Elder recommended such beverages in the treatment of gastro-intestinal disorders. The first attempt to scientifically explain beneficial effects of yogurt on the human body was made by Ilya Mechnikov (associate of Louis Pasteur), who claimed that the bacteria contained in yogurt displace the intestinal toxinogenic bacteria and thus affect the long life in good health, giving rise to the so-called "theory of longevity" [7].

Correspondence: Wioletta Żukiewicz-Sobczak, Department of Alergology and Environmental Hazards, Institute of Rural Health, Jaczewskiego 2, 20-090 Lublin, e-mail: wiola.zukiewiczsobczak@gmail.com 
The term probiotic defines specific strains of microorganisms, which when administered to humans and animals have a beneficial impact on their bodies. These bacteria are mainly derived from the human gastrointestinal tract, mostly gram-positive, anaerobic rods, mainly belonging to lactic acid bacteria of the Lactobacillus and Bifidobacterium genera [8]. Probiotics are available in the form of pharmaceutical preparations (tablets, capsules, ampoules) or in the form of food or food supplements, which contain a precise number of viable bacteria of a particular probiotic strain [9].

Lactic acid bacteria (LAB) are commonly used for the production of fermented dairy products, vegetables or meat. The strains used in the production of fermented food or pharmaceuticals must be recognized as safe, holding the GRAS (Generally Recognised As Safe) status. They must also have a number of features in the aspects of safety, functional and technological characteristics. Lactic acid bacteria used in probiotic preparations are derived from the human gastrointestinal tract, are accurately identified, with a history of safe use and are not the subject of any reports of their potential pathogenicity or antibiotic resistance. Important functional properties of probiotic LAB include their resistance to acidic gastric juices, capacity of adhesion to the walls of the gastrointestinal tract and antagonistic action against pathogenic microorganisms which might endanger the human $[10,11]$. The effect of probiotic bacteria on the intestinal flora is associated with the metabolism of lactic acid bacteria. Carbohydrate substrates are mainly subject to fermentation, breaking down to mainly lactic acid and short chain fatty acids such as butyric acid, acetic acid or propionic acid lowering the $\mathrm{pH}$ of the intestinal contents [12]. In addition, some lactic acid bacteria secrete substances with a bacteriostatic effect such as $\mathrm{H}_{2} \mathrm{O}_{2}$ and bacteriocins called lactocins (e.g. nisin, acidophilin, lactacin, lactocidin) thus preventing the development of pathogenic micro-organisms [13].

The species with the best documented probiotic properties are: Lactobacillus rhamnosus, Lactobacillus acidophilus, Lactobacillus casei, Lactobacillus delbrueckii subsp. bulgaricus, Lactobacillus plantarum, Bifidobacterium bifidum, Bifidobacterium lactis, Lactococcus lactis and Leuconostoc mesenteroides. These bacteria are used in the form of pharmaceutical preparations or as starter cultures in the production of probiotic foods, mainly fermented dairy products [14].

Lactic acid bacteria colonize the gastrointestinal tract of every healthy person and seal it against the attack of pathogenic microorganisms. However, the fetal gastrointestinal tract is sterile during fetal life. The composition of the intestinal microflora is established only after the birth. At 7-10 days of age it includes lactic acid bacteria of the Bifidobacterium genus mainly from mother's milk. Therefore, it is important to breastfeed because it provides a suitable composition of intestinal microflora and protects child from pathogens. According to the research, in breastfed infants there were up to 10 -fold more bifidobacteria in the gut microbiota compared with infants fed with artificial mixtures [15]. The composition of the microflora in a 2-year-old child to a large extent resembles the flora of a healthy adult human [16]. During infancy and later in life, the digestive tract is constantly exposed to large quantities of various bacteria and their metabolites. Probiotics have an effect on the intestinal epithelium itself as well as humoral and cellular immune mechanisms, and therefore affect the expression of allergic disease [17, 18]. Intestinal epithelial cells play an important role in antigen presentation penetrating the body orally, and in the regulation of the intestinal immune response [19]. It is worth noting that the composition and quantity of bacteria depends on many factors including the age, hormonal regulation, environment, eating habits and health status [20].

The intestinal microflora affects the body through the lymphatic system GALT (Gut Associated Lymphoid Tissue), which is an integral part of the immune system closely related to the gastrointestinal tract. System GALT is also related to the mucous membranes associated with the lymphatic system MALT (Mucosa Associated Lymphoid Tissue) [21]. Immunological mechanisms of probiotics is associated with reducing the inflammatory response by modifying the presentation of the antigen promoting the differentiation of Th1 cells, NK cells and macrophage activation, increasing the expression of the genes encoding interleukin 8 (IL-8) and tumor necrosis factor $\alpha$ (TNF- $\alpha$ ), stimulating and increasing the phagocytic activity [22]. In terms of prevention of allergy, probiotics also affect the increased secretion of immunoglobulin (Ig) A antibodies in the Peyer's patches, which protect the intestinal mucosa from the effects of food allergens, thereby reducing the inflammatory response. It was shown that lactic acid bacteria may affect the immunomodulatory properties of the proteins present in the food, leading to the reduction of $\operatorname{IgE}$ secretion and eosinophil activation [23]. The most effective is the administration of probiotics with prebiotics (i.e. synbiotics), since this addition makes the probiotic bacteria in the intestinal transit restore the balance of intestinal microflora and the prebiotic - which is a substrate for these non-digestible extends the operating time and stimulates growth. The most commonly used prebiotics include fructooligosaccharides (FOS), galacto-oligosaccharides (GOS), inulin and lactulose [24, 25].

Bjorksten et al. found significant correlations between the composition of intestinal microflora and the incidence of allergic diseases. The researchers analyzed the comparative intestinal microflora of Swedish and Estonian children and its influence on the incidence of allergies. In children with allergic symptoms, a reduced number of bacteria of the Lactobacillus and Bacteroides genera was reported and aerobic bacteria Escherichia coli and Staphylococcus aureus were more frequent [26]. In a similar study. 
Sepp et al. showed that in Estonian children bacteria of the Lactobacillus and Eubacterium genera prevailed, and the Clostridium genus in Swedish children. In Sweden, a higher proportion of allergy was observed comparing to Estonia, what confirms the 'hygiene hypothesis' as a cause of allergies, showing the relation of lifestyle and quality of intestinal colonization which affects the development of the immune system [27].

Food allergy is often observed in infancy, particularly hypersensitivity to lactose contained in milk [28-31]. Probiotics are often used to relieve the symptoms of food allergy, especially in children with lactose intolerance. According to the European Society for Pediatric Gastroenterology, Hepatology and Nutrition (ESPGHAN), for the treatment of hypersensitivity to cow's milk protein only blends with a high degree of hydrolysis of both casein and whey protein are used. In severe food allergies one should use a mixture of amino acids (amino acid formula - AAF), which are devoid of almost any allergenic force. Preparations for the treatment of hypersensitivity to cow's milk proteins are enriched with active immunomodulatory probiotics (mainly Lactobacillus rhamnosus GG) [32]. One of the first clinical trials examining the effects of probiotics in the treatment of allergic diseases took place in 1997 where two groups of infants with atopic eczema and allergy to cow's milk protein were compared. Infants were fed with a hydrolyzed dairy-free formula, but in some children with Lactobacillus GG added. Observations of skin lesions were performed for a period of four weeks, which showed a significant clinical improvement. Simultaneously, a decrease in the concentration of $\alpha 1$-antitrypsin and TNF- $\alpha$ in the feces was found [33].

Another clinical study involved infants who developed symptoms of atopic eczema during breast-feeding, and children were not formula fed. Children were subjected to two months of supplementation with Lactobacillus rhamnosus GG and Bifidobacterium lactis Bb12. A significant clinical improvement and a reduction in the concentration of CD4 (T-cell activation marker) as well as levels of factor TGF- $\beta 1$ (transforming growth factor $\beta 1$ ), which mediates the production of $\operatorname{IgA}$ antibodies in infants was shown. Researchers have observed a significant reduction in atopic eczema as a result of SCORing Atopic Dermatitis (SCORAD) decline from 16 points to 0 (B. lactis) or 1 (L-GG). All observations of this experiment confirm the possibility of modulating the immune response by probiotics [34]. Similar results were obtained by other authors who have used L. fermentum VRI-003 PCC. A reduction in SCORAD in $92 \%$ of treated children with skin lesions was demonstrated [35].

Kalliomäki et al. conducted a long-term study on the impact of probiotics on the risk of atopic eczema. Pregnant women with an allergy history were given the probiotic Lactobacillus GG for 2-4 weeks before birth and for the next six months after birth if breastfeeding, otherwise infants formula fed were supplemented. Due to systematically administered probiotics, a risk of atopic eczema in children aged 2 years decreased 2 -fold. In subsequent years, in children aged 4 and 7 years, the risk of eczema was also reduced. There was no difference in the incidence of inhalation allergies or significant changes in serum IgE levels [36-38]. Similar observations were made by other researchers. They showed reduced symptoms of atopic eczema in a group of 2-year-olds who took synbiotic preparations containing probiotic Lactobacillus strains in conjunction with galacto-oligosaccharides as a prebiotic [39]. A Polish research of Cukrowska et al. determined the effect of Lactobacillus case $i$ and L. paracasei on the severity of symptoms in both IgE-dependent and IgE-independent atopic eczema. Children in the test group took probiotics for 3 months in a daily dose of $10^{9}$ cells while the control group received casein hydrolyzate. The clinical condition of children was assessed both before and after the study by SCORAD. Only in children with IgE-mediated atopic eczema, administration of probiotics affected the clinical improvement observed in $93 \%$ of children [40].

The impact of the adoption of probiotics in children aged 1-13 years in the course of atopic dermatitis was also examined. Subjects were administered Lactobacillus reuteri and Lactobacillus rhamnosus, and concentrations of cytokines: interleukin (IL)-2, IL-4, IL-10 and interferon $\gamma$ (INF- $\gamma$ ) and sECP (soluble eosinophil cationic protein) were subject to assessment and in patients receiving probiotics a significant health improvement has been observed and also a reduction in SECP that is released by activated eosinophils and they are often used to monitor the exacerbations of atopic dermatitis [41].

The results of many studies showed that the effect of probiotics depends on species of bacteria, and sometimes even the strain $[42,43]$. Wickens et al. conducted a double-blind large trial with placebo and administered to pregnant women with a history of atopy B. lactis subsp. animalis strain HN019 and L. rhamnosus strain HN001 from the $35^{\text {th }}$ week of pregnancy, and for six months after birth if women breastfed. The same probiotics were administered to children from birth to the age of 2 years. In both groups of children, there was a similar incidence of atopy, while a significantly lower proportion (approximately 50\%) of cases of atopic dermatitis in children treated with supplementation with L. rhamnosus, and the lack of effect of alleviating eczema when supplementing $B$. animalis lactis. It demonstrates their effectiveness in pediatric patients for the prevention of AD combined prenatal and postnatal supplementation with probiotic containing L. rhamnosus strain HN001 [44]. Tests to determine the possibility of the use of probiotics in the treatment and prevention of atopic dermatitis are immensely important because now this disease affects about $18 \%$ of children and $5 \%$ of adults, according to the study population $[45,46]$. 
There are a few tests to determine the role of probiotics in allergic diseases other than atopic dermatitis and food allergies. However, the study of Trapp et al. showed a positive effect of yogurt containing probiotic bacterial cultures for alleviating the symptoms of allergic rhinitis in adults [47].

We also examined the effect of administering milk containing Lactobacillus casei strain Shirota (LcS) to alleviate the symptoms of allergy to grass pollen. The subjects had a supplementation period of 5 months prior to, during, and after pollination, and were marked with their levels of $\operatorname{IgG}$ and $\operatorname{IgE}$ (total and specific to grass pollen) during the entire study. The test group had a decrease in IL-5, IL-6 and IFN- $\gamma$ and significantly lower levels of IgE and higher levels of IgG compared to the placebo group, indicating a beneficial effect of probiotic microorganisms on prevention and weakening of allergic reaction to grass pollen [48].

Unfortunately, in patients suffering from bronchial asthma mediocre clinical effects of supplementation with probiotics were observed. In one of the studies comparing the effects of placebo and supplementation of $L$. casei researchers have demonstrated a beneficial effect on the symptoms of allergic rhinitis, but not asthma [49]. Similar results were obtained by Wheeler et al. examining the impact of eating yogurt rich in L. acidophilus on asthma symptoms. A significant effect on the intensity of the symptoms was not observed, especially in lung function parameters. At the same time, however, normalization of serum IgE, IL-2 and IL-4 in the serum was observed [50].

\section{Summary}

There is a significant clinical effect differences in longterm supplementation with probiotics in relation to species and even the strain of lactic acid bacteria. Efficacy and safety of specific probiotic strains should be confirmed both in vitro, in animals and in randomized, double-blind placebo-controlled clinical trials.

Variable effects of LAB in the prevention and treatment of allergic diseases show great differences in mechanisms of their action. Specific effects through the use of probiotic preparations are dependent on important factors such as the number and viability of microorganisms in the human digestive system, the time spent in the gut and composition of microflora already present in the gut. All these factors affect the ability to induce a specific response from the immune system.

Taking probiotics, both in the form of pharmaceutical preparations and foods such as fermented milk drinks is an effective method for prevention and treatment of allergies. The effectiveness of probiotics is higher in the case of prevention of allergy in comparison to their capacity to alleviate the existing symptoms of allergy. The principal benefits of probiotics beyond their proven effectiveness are the safety of their use (including children and infants) and lack of side effects.

Since the allergy is becoming a common problem it is extremely important to carry out further research evaluating health-promoting effects of probiotic strains and the possibility of their use in the prevention and treatment of many diseases, including allergic ones.

\section{Authors declare no conflict of interest}

\section{References}

1. Steciwko A, Pokorna-Kałwak D, Muszyńska A (2009): The significance of allergology in family medicine. Post Dermatol Alergol 26: 364-366 (Polish).

2. Żukiewicz-Sobczak W, Krasowska E, Zwoliński J, et al. (2012): Allergic diseases - current state of knowledge. Postep Derm Alergol 29: 451-455.

3. Zukiewicz-Sobczak W (2013): The role of fungi in allergic diseases. Postepy Dermatol Alergol 30: 42-45.

4. Kamer B, Pasowska R, Dółka E, et al. (2013): Prevalence of atopic dermatitis in infants during the first six months of life: authors' observations. Postepy Dermatol Alergol 30: 277-281.

5. Żukiewicz-Sobczak W, Krasowska E, Zwoliński J, et al. (2012): Allergic diseases - current state of knowledge. Postepy Dermatol Alergol 29: 451-455.

6. Marchand J, Vanderplas Y (2000): Microorganisms administered in the benefit of the host: myths and facts. Eur J Gastroenterol Hepatol 12: 1077-1088.

7. Oberman H (2004): Lactic acid bacteria yesterday and today. In: Lactic acid bacteria-classification metabolism, genetics, use. Libudzisz Z, Walczak P, Bardowski J (eds.). Publisher University of Lodz, Lodz; 7-25 (Polish).

8. O’May GA, Macfarlane GT (2005): Health claims accociated with probiotics. In: Probiotic Dairy Products. Tamine A (eds.). Blackwell Publishing, London; 138-166.

9. Furrie E (2005): Probiotics and allergy. Proc Nutr Soc 64: 465-469.

10. Libudzisz Z (2004): Human intestinal microflora and probiotics. Zakażenia 6: 47-51 (Polish).

11. Piątek J, Gibas-Dorna M, Olejnik A, et al. (2012): The viability and intestinal epithelial cell adhesion of probiotic strain combination - in vitro study. Ann Agric Environ Med 19: 99-102.

12. Stolarczyk A, Socha P, Socha R (2002): Probiotics and prebiotics in the prevention and treatment of diseases in children. Terapia 116: 39-42 (Polish).

13. Jack RW, Tagg JR, Ray B (1995): Bacteriocins of Gram-positive bacteria. Microbiol Rev 59: 171-200.

14. Holzapfel WH, Geisen R, Bjorkroth J, Schillinger U (2001): Taxonomy and important features of probiotic microorganisms in food and nutrition. Am J Clin Nutr 73: 365-373.

15. Libudzisz Z (2010): The human gastrointestinal tract microflora and its effect on the organism. In: Microorganisms in food and nutrition. Gawęcki J, Libudzisz Z (eds.). Publisher University of Life Science in Poznań, Poznan; 31-40 (Polish).

16. Bezirtzoglou E (1997): The intestinal microflora during the first weeks of life. Anaerobe 3: 173-177.

17. Capurso L (2001): Probiotics and prebiotics and food intolerance. Allergy 56: 125-126. 
18. Paganelli R, Ciuffreda S, Verna N, et al. (2002): Probiotics and food-allergic disease. Allergy 57: 97-99.

19. Banasaz M, Norin E, Holma R, Midtvedt T (2002): Increased enterocyte production in gnotobiotic rats mono-associated with Lactobacillus rhamnosus GG. Appl Environ Microbiol 68: 3031-3034.

20. De Moreno de LeBlanc A, Dogi CA, Galdeano CM, et al. (2008): Effect of the administration of a fermented milk containing Lactobacillus casei DN-114001 on intestinal microbiota and gut associated immune cells of nursing mice and after weaning until immune maturity. BMC Immunol 9: 27.

21. Tlaskalova-Hogenova H, Stepankova R, Hudcovic T, et al. (2004): Commensal bacteria (normal microflora), mucosal immunity and chronic inflammatory and autoimmune diseases. Immunol Lett 93: 97-108.

22. Erickson KL, Hubbard NE (2000): Probiotic immunomodulation in health and disease. J Nutr 130: 403-409.

23. Kirjavainen PV, Apostolou E, Salminen SJ, Isolauri E (1999): New aspects of probiotics - a novel approach in the management of food allergy. Allergy 54: 909-915.

24. Krawczyński M (2003): Probiotics, prebiotics and functional foods. Przew Lek 6: 110-115 (Polish).

25. Bengmark S (2012): Integrative medicine and human healththe role of pre-, pro and synbiotics. Clin Transl Med 1: 6 .

26. Bjorksten B, Naaber P, Sepp E, Mikelsaar M (1999): The intestinal microflora in allergic Estonian and Swedish 2-yearold children. Clin Exp Allergy 29: 342-346.

27. Sepp E, Julge K, Vasar M, et al. (1997): Intestinal microflora of Estonian and Swedish infants. Acta Paediatr 86: 956-961.

28. Żukiewicz-Sobczak W, Wróblewska P, Adamczuk P, Kopczyński P (2013): Causes, symptoms and prevention of food allergy. Postepy Dermatol Alergol 30: 113-116.

29. Kaczmarski M, Żur E, Kondej-Muszyńska K (2012): Therapeutic and nutritional applications of amino acid-based elemental formulas in children with food allergies: a preliminary report. Postepy Dermatol Alergol 29: 86-93.

30. Nowacki Z (2012): Patient characteristics of children with cow's milk allergy presenting with an allergy to extensively hydrolyzed whey and/or casein formulae used as part of an elimination diet. Postepy Dermatol Alergol 29: 421-431.

31. Graczyk M, Przybyszewski M, Kuźmiński A, et al. (2013): Role of E-selectin and platelet endothelial cell adhesion molecule 1 in gastritis in food allergy patients. Postepy Dermatol Alergol 30: 271-276.

32. ESPGHAN Committee on Nutrition; Agostoni C, Axelsson I, Goulet O, et al. (2006): Soy protein infant formulae and follow-on formulae: a commentary by the ESPGHAN Committee on Nutrition. J Pediatr Gastroenterol Nutr 42: 352-361.

33. Majamaa H, Isolauri E (1997): Probiotics: A novel approach in the management of food allergy. J Allergy Clin Immunol 99: 179-185.

34. Isolauri E, Arvola T, Sutas Y, et al. (2000): Probiotics in the management of atopic egzema. Clin Exp Allergy 30: 16041610.

35. Weston S, Halbert AR, Richmond P, Prescott SL (2005): Effects of probiotics on atopic dermatitis: a randomised controlled trial. Arch Dis Child 90: 892-897.

36. Kalliomaki M, Salminen S, Arvilommi H, et al. (2001): Probiotics in primary prevention of atopic disease: a randomised placebo-controlled trial. Lancet 357: 1076-1079.

37. Kalliomaki M, Salminen S, Poussa T, et al. (2003): Probiotics and prevention of atopic disease: 4 year follow-up of a randomised placebo-controlled trial. Lancet 361: 1869-1871.
38. Kalliomaki M, Salminen S, Poussa T, Isolauri E (2007): Probiotics during the first 7 years of life: a cumulative risk reduction of eczema in a randomized, placebo- controlled trial. J Allergy Clin Immunol 119: 1019-1021.

39. Kukkonen K, Savilahti E, Haahtela T, et al. (2007): Probiotics and prebiotics galacto-oligosaccharides in the prevention of allergic disease: a randomized, double-blind, placebo-controlled trial. J Allergy Clin Immunol 119: 192-198.

40. Cukrowska B, Ceregra A, Rosiak I, et al. (2008): The influence of probiotic Lactobacillus casei and paracasei strains on clinical status of atopic eczema in children with food allergy on cow's milk proteins. Pediatr Współcz 10: 67-70 (Polish).

41. Rosenfeldt V, Benfeldt E, Nielsen S, et al. (2003): Effect of probiotic Lactobacillus strains in children with atopic dermatitis. J Allergy Clin Immunol 111: 389-395.

42. Vanderhoof JA, Young RJ (2003): Role of probiotics in the management of patients with food allergy. Ann Allergy Asthma Immunol 90: 99-103.

43. del Giudice MM, De Luca MG (2004): The role of probiotics in the clinical management of food allergy and atopic dermatitis. J Clin Gastroenterol 38: 84-85.

44. Wickens K, Black PN, Stanley TV, et al. (2008): A differential effect of 2 probiotics in the prevention of eczema and atopy: A double-blind, randomized, placebo-controlled trial. J Allergy Clin Immunol 122: 788-794.

45. Silny W, Bartoszak L, Jenerowicz D, et al. (2013): Prevalence of contact allergy in children suffering from atopic dermatitis, seborrhoeic dermatitis and in healthy controls. Ann Agric Environ Med 20: 55-60.

46. Polańska A, Dańczak-Pazdrowska A, Silny W, et al. (2012): Evaluation of selected skin barrier functions in atopic dermatitis in relation to the disease severity and pruritus. Postepy Dermatol Alergol 29: 373-377.

47. Trapp CL, Chang CC, Halpern GM, et al. (1993): The influence of chronic yogurt consumption on populations of young and elderly adults. Int J Immunother 9: 53-64.

48. Ivory K, Chambers SK, Pin C, et al. (2008): Oral delivery of Lactobacillus casei Shirota modifies allergen-induced immune responses in allergic rhinitis. Clin Exp Allergy 38: 1282-1289.

49. Giovannini M, Agostoni C, Riva E, et al. (2007): A randomized prospective double blind controlled trial on effects of long-term consumption of fermented milk containing Lactobacillus casei in pre-school children with allergic asthma and/ or rhinitis. Pediatr Res 62: 215-220.

50. Wheeler JG, Shema SJ, Bogle ML, et al. (1997): Immune and clinical impact of Lactobacillus acidophilus on asthma. Ann Allergy Asthma Immunol 79: 229-233. 